\title{
Mechanical and Microstructural Characterization of Ultrasonic Welded NiTiCu Shape Memory Alloy Wires to Silver-Coated Copper Ferrules
}

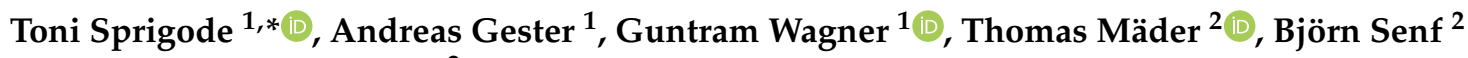 \\ and Welf-Guntram Drossel ${ }^{2}$ \\ 1 Chair of Composites and Material Compounds, Institute of Materials Science and Engineering, Chemnitz \\ University of Technology, 09125 Chemnitz, Germany; andreas.gester@mb.tu-chemnitz.de (A.G.); \\ Guntram.wagner@mb.tu-chemnitz.de (G.W.) \\ 2 Fraunhofer Institute for Machine Tools and Forming Technology IWU, 01187 Dresden, Germany; \\ thomas.maeder@iwu.fraunhofer.de (T.M.); bjoern.senf@iwu.fraunhofer.de (B.S.); \\ welf-guntram.drossel@iwu.fraunhofer.de (W.-G.D.) \\ * Correspondence: toni.sprigode@mb.tu-chemnitz.de
}

check for updates

Citation: Sprigode, T.; Gester, A.; Wagner, G.; Mäder, T.; Senf, B.; Drossel, W.-G. Mechanical and Microstructural Characterization of Ultrasonic Welded NiTiCu Shape Memory Alloy Wires to Silver-Coated Copper Ferrules. Metals 2021, 11, 1936. https://doi.org/10.3390/ met11121936

Received: 27 October 2021 Accepted: 24 November 2021 Published: 30 November 2021

Publisher's Note: MDPI stays neutral with regard to jurisdictional claims in published maps and institutional affiliations.

Copyright: (c) 2021 by the authors. Licensee MDPI, Basel, Switzerland. This article is an open access article distributed under the terms and conditions of the Creative Commons Attribution (CC BY) license (https:/ / creativecommons.org/licenses/by/ $4.0 /)$.

\begin{abstract}
The aim of this study was to investigate the mechanical behavior, and the microstructure of NiTiCu shape memory alloy wires joined with silver-coated copper ferrules via ultrasonic spot welding. Therefore, the electrical resistance was measured during tensile testing, and the joints were analyzed by scanning electron microscopy. Energy-dispersive X-ray spectroscopy has determined the compounds of the developed welding zones. Furthermore, the influence of the ultrasonic welding on the transition temperatures of the NiTiCu wires was examined via differential scanning calorimetry. Tensile tests have shown that the ultimate tensile strengths of the joints reached almost $100 \%$ of that of the base material. An additional heat treatment rebuilt the typical shape memory alloy behavior after the ultrasonic welding process detwinned the martensitic wires. In addition, the B19' structure of the welding zone and the ultrasonic spot-welding process did not affect the transition temperatures of the shape memory alloy.
\end{abstract}

Keywords: ultrasonic metal welding; shape memory alloys; mechanical and microstructural properties; transition temperature

\section{Introduction}

Shape memory alloys (SMAs) are often used as actuators [1-3] in automotive, aerospace and biomedical fields [4-7] because of their ability to convert thermal energy into mechanical energy. This effect is the result of the reversible and diffusionless solid-solid phase transformation between the martensitic low-temperature phase and the austenitic high-temperature phase. As soon as the austenite start temperature $A_{s}$ is exceeded, the high-temperature phase begins to form until the austenite finish temperature $A_{f}$ is reached. Because of the thermal hysteresis, the martensite start temperature $M_{s}$ and the finish temperature $M_{f}$ are not the same as the transition temperatures of the high-temperature phase.

If martensitic SMAs are plastically deformed and afterward heated up above $A_{f}$, all deformations are removed, and the alloy "remembers" its initial shape. In addition, SMAs can be trained to remember their shape in the low-temperature phase, too. In this case, they switch between both forms by heating and cooling. Furthermore, the alloys show a pseudoelastic behavior in the austenitic high-temperature phase because of the phase transformation to stress-induced martensite. This means that the strain goes up to $10 \%$ [8] while the specimen is stressed. After unloading, the extension decreases at lower stress values due to mechanical hysteresis.

$\mathrm{NiTi}$ is the most important SMA for commercial applications. Aside from the pronounced shape memory effect, the material is biocompatible and has excellent resistance to 
corrosion [9]. The addition of copper to the binary system reduces the quantity of nickel [9] and influences the properties. One result of the additional element is shown in a decrease of the thermal hysteresis. Furthermore, the mechanical hysteresis during the pseudoelasticity diminishes too, and the thermo-mechanical cycling stability grows [10]. Moreover, if the quantity of copper exceeds 10 at.\%, then the material begins to embrittle [9].

To join SMAs with similar and dissimilar materials, fusion welding processes, such as tungsten inert gas welding [11,12] or electron beam welding [13,14], are often applied. Laser beam welding is used especially frequently because of the high welding speed and the minimal heat input. However, all fusion welding processes show some problems. For example, brittle intermetallic compounds emerge, the joint strength decreases, and the transformation temperatures change [15]. Falvo et al. [16] joined two similar NiTi sheets with an Nd:YAG laser. As a result of this process, the material embrittled, and the ultimate tensile strength was reduced by more than $50 \%$, down to $520 \mathrm{MPa}$. However, Zeng et al. [17] produced laser beam-welded composites of wires and tubes with similar and dissimilar NiTi alloys. The resulted joint break force for both combinations amounted to over $70 \%$ in comparison to the base material (BM). Additionally, the phase transformation temperatures were varied after the welding process. The $A_{f}$ and $M_{f}$ of the similar material joints increased from 19.25 to $91.7^{\circ} \mathrm{C}$ and -12.7 to $29.1^{\circ} \mathrm{C}$, respectively.

In order to reduce the negative influences of the fusion welding, novel approaches, such as solid-state methods, such as friction stir welding [18,19] or adhesive bonding [20,21], should be used for joining. Another useful and promising solid-state process is ultrasonic spot welding (USW) because of the very short welding time, the low-heat input and the resulting minimal electrical contact resistance. Zhang et al. [22] investigated the mechanical behavior of similar ultrasonic welded NiTi sheets. They noted that the process did not generate detrimental intermetallic compounds. Additionally, the highest tensile load was more than $50 \%$ in comparison to the BM. This was a result of the partially-bonded weld interface, which is typical for USW. However, minimally-varied phase transition temperatures were achieved. In another study from Zhang et al. [23], similar results were achieved by using a copper interlayer between NiTi sheets. No intermetallic compounds were noticed after USW and the joint strength increased due to the interlayer up to $64 \%$ compared to the BM.

The intention of this study is to create strong ultrasonic welded joints of NiTiCu SMA wires and silver-coated ferrules. These joints should have a low electrical resistance to conduct electricity through the ferrules to the wires, causing them to heat up, change shape, and move as an actuator. Therefore, the optimal welding parameters were determined by a design of experiments (DoE). Furthermore, tensile tests accompanied by electrical resistance measuring were carried out, and the resulting joints were investigated by scanning electron microscopy (SEM), energy-dispersive X-ray spectroscopy (EDS) and differential scanning calorimetry (DSC).

\section{Materials and Methods}

In this study, wires with a diameter of $200 \mu \mathrm{m}$ consisting of a NiTiCu SMA were joined with a silver-coated copper ferrule by ultrasonic spot welding. Preliminary EDS has shown that the wire is composed of 49 at.\% titanium, 43 at.\% nickel, 8 at.\% copper and less than 0.01 at.\% of other elements. Furthermore, DSC of the SMA was carried out before and after USW by a cooling and heating rate of $10 \mathrm{~K} / \mathrm{min}$ in a nitrogen atmosphere. The results revealed that the transition temperatures of the $\mathrm{BM}$ are $A_{s}=49.42, A_{f}=55.61, M_{S}=41.26$ and $M_{f}=33.4{ }^{\circ} \mathrm{C}$. That means that the wire is in the state of the low-temperature phase at room temperature. Furthermore, the specimens were heated and cooled for five repetitions to evaluate stabilizing effects.

The second joining partner was a silver-coated copper ferrule with a length $l$ of $5 \mathrm{~mm}$, an inner diameter $d 1$ of $1 \mathrm{~mm}$, an outer diameter $d 2$ of $1.8 \mathrm{~mm}$ and a wall thickness $s$ of $0.2 \mathrm{~mm}$. Its dimensions are shown in Figure 1. 


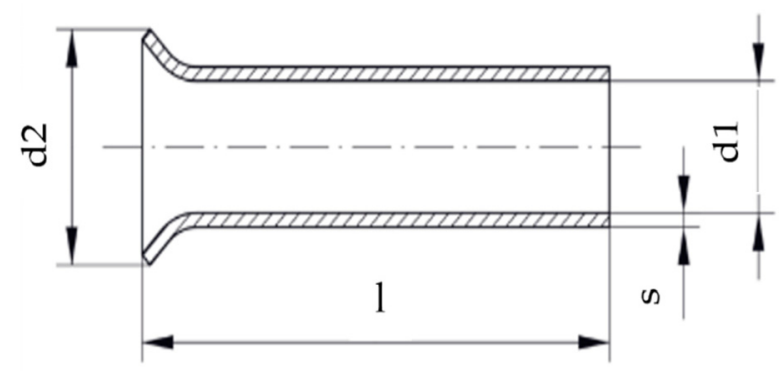

Figure 1. Dimensions of the silver-coated copper ferrules.

The wires were welded to the ferrules by a linear USW machine MPX-50-2 (Telsonic $\mathrm{GmbH}$, Bronschhofen, Switzerland). This device had a maximum generator power of $6.5 \mathrm{~kW}$ and could weld wires with diameters between $20 \mu \mathrm{m}$ and $2 \mathrm{~mm}$. The SMA wires were threaded through the ferrules and placed under the horn. In order to fix the wires, the wire ends have been clamped firmly. A total of six joints have been developed, three each for examination with and without subsequent heat treatment.

The determination of optimum welding parameters for joining the NiTiCu wires and the silver-coated ferrules took place by using a DoE and an analysis of means (ANOM). For this purpose, three levels were selected for each welding parameter (Table 1), and a total of nine parameter sets with different parameter levels were created. Each parameter set was welded three times. The results of the following tensile tests on these samples (Table 2) formed the basis of the ANOM. This analysis calculated the optimal welding parameters, which were used subsequently to investigate the joints. They are shown in Table 3.

Table 1. Parameter levels for each welding parameter.

\begin{tabular}{cccc}
\hline Welding Parameters & Level 1 & Level 2 & Level 3 \\
\hline A. Welding pressure $(\mathrm{Pa})$ & 40,000 & 50,000 & 60,000 \\
B. Belding force $(\mathrm{N})$ & 60 & 100 & 160 \\
C. Amplitude $(\mu \mathrm{m})$ & 12 & 16 & 20 \\
D. Welding energy $(\mathrm{J})$ & 30 & 60 & 90 \\
\hline
\end{tabular}

Table 2. Parameter sets with ultimate tensile strength (UTS) of their welded joints and the average UTS of the parameter sets.

\begin{tabular}{ccccccccc}
\hline & & Welding Parameters & & $\begin{array}{c}\text { UTS } \\
\text { Joint 1 }\end{array}$ & $\begin{array}{c}\text { UTS } \\
\text { Joint 2 }\end{array}$ & $\begin{array}{c}\text { UTS } \\
\text { Joint 3 }\end{array}$ & $\begin{array}{c}\text { Average } \\
\text { UTS }\end{array}$ \\
\cline { 2 - 9 } & A & B & C & D & $\mathbf{( M P a )}$ & $\mathbf{( M P a )}$ & $\mathbf{( M P a )}$ & $\mathbf{( M P a )}$ \\
\hline 1 & 1 & 1 & 1 & 1 & 807.28 & 621.76 & 698.51 & 709.18 \\
2 & 1 & 2 & 2 & 2 & 700.77 & 525.38 & 751.23 & 659.13 \\
3 & 1 & 3 & 3 & 3 & 254.08 & 824.65 & 828.31 & 635.68 \\
4 & 2 & 1 & 2 & 3 & 574.24 & 547.74 & 707.74 & 609.91 \\
5 & 2 & 2 & 3 & 1 & 836.97 & 496.92 & 519.81 & 617.90 \\
6 & 2 & 3 & 1 & 2 & 738.84 & 463.76 & 731.34 & 644.65 \\
7 & 3 & 1 & 3 & 2 & 416.53 & 684.8 & 830.51 & 643.95 \\
8 & 3 & 2 & 1 & 3 & 299.94 & 612.68 & 469.18 & 460.60 \\
9 & 3 & 3 & 2 & 1 & 718.16 & 751.95 & 577.15 & 682.42 \\
\hline
\end{tabular}

Table 3. Optimum welding parameters for joining NiTiCu SMA wires to silver-coated ferrules.

\begin{tabular}{ccc}
\hline Welding Parameters & Level & Value \\
\hline Welding pressure & 1 & $40,000 \mathrm{~Pa}$ \\
Welding force & 1 & $60 \mathrm{~N}$ \\
Amplitude & 2 & $16 \mu \mathrm{m}$ \\
Welding energy & 1 & $30 \mathrm{~J}$ \\
\hline
\end{tabular}


After welding, the specimens were mechanically and microstructurally investigated. Therefore, the tensile testing machine ProLine (ZwickRoell GmbH \& Co. KG, Ulm, Germany) was used to study the mechanical behavior of the wires by a cycle speed of $0.1 \% / \mathrm{s}$. The resulted stress was calculated by dividing the measured force by the cross-sectional area of the wire. For determining the elongation, the distance between the fixed joint and the clamped wire end was examined. To clamp the specimen, the wires of the BM were crimped with a ferrule on each end and then fixed in luster terminals, which were fastened in the restraints of the tensile testing machine. This allows both luster terminals to be connected to a resistance meter. Regular clamping of the tensile testing machine is not expedient for evaluating the tensile strength of this joint type. Therefore, a clamping application was built out of a carbon-fiber-reinforced plastic cuboid, which had a $0.3 \mathrm{~mm}$ drilled hole at the front. Thus, the wire was led through the hole while the movement of the welded ferrule was prevented by the cuboid (Figure 2b). In addition, the application is clamped at the top of the tensile testing machine, and the wire end is fixed in a luster terminal at the bottom. This luster terminal and the welded ferrule were connected with a resistance meter to measure the electrical resistance while tensile testing.

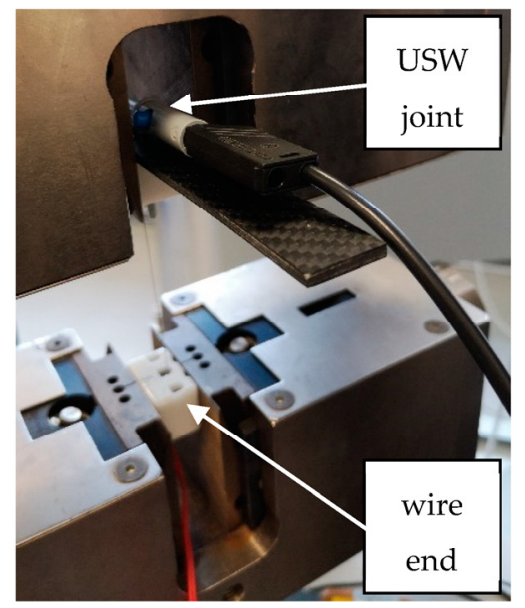

(a)

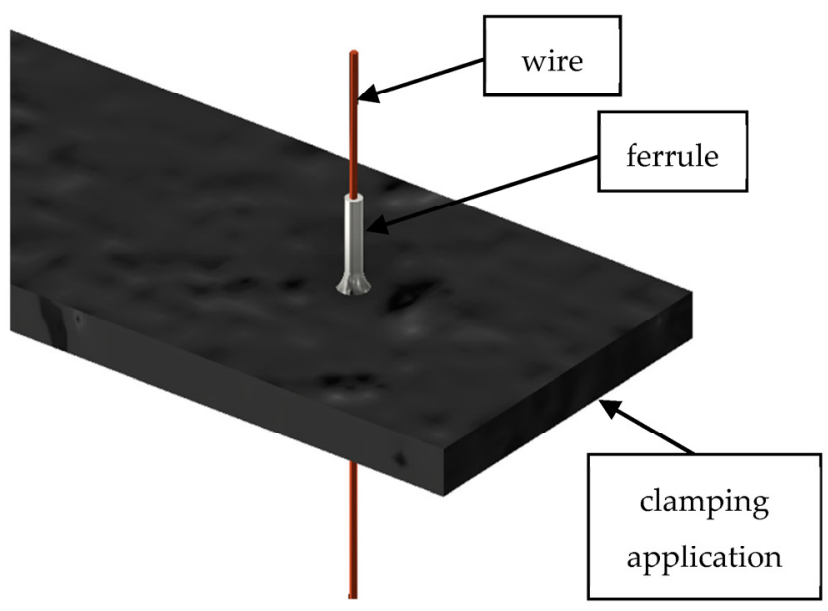

(b)

Figure 2. (a) Clamping and contacting of the welded joints in the tensile testing machine; (b) 3D model of the joint held by the clamping application.

For the microstructural investigations, the scanning electron microscope ZEISS LEO1455VP (Carl Zeiss AG, Oberkochen, Germany) was used, and all recordings were taken at an acceleration voltage of $25 \mathrm{keV}$. Furthermore, the EDS of the BM and the welded joint was carried out on the same microscope in order to analyze whether the USW process had influenced the composition of the phases.

\section{Results}

\subsection{Tensile Tests}

The BM of the NiTiCu wires showed a typical SMA behavior. An initially linear-elastic expansion is followed by the martensite plateau, which is maintained up to a maximum of $2.5 \%$ elongation at approx. $50-60 \mathrm{MPa}$. After all of the martensite was detwinned, the second linear-elastic expansion followed up to an elongation of $9 \%$ at $850 \mathrm{MPa}$. The ultimate tensile strength of the $\mathrm{BM}$ was reached at $996 \mathrm{MPa}$ and an elongation of $20 \%$.

In comparison to the BM, the US welded joints did not behave as an SMA (Figure 3). They showed no typical martensite plateau with a long elongation at a nearly constant stress. Furthermore, the elongation of the welded joints was reduced and amounted to a maximum of $12.5 \%$. At two of the three joints, the wires were gradually pulled out of the ferrules, which led to an inconsistent stress/elongation behavior, shown in Figure 3. These joints exhibited an ultimate tensile strength of 558 and $651 \mathrm{MPa}$, respectively. However, 
only one joint broke in the center of the wire at a stress of $988 \mathrm{MPa}$, which corresponds to an ultimate tensile strength of $99 \%$ in comparison to that of the BM.

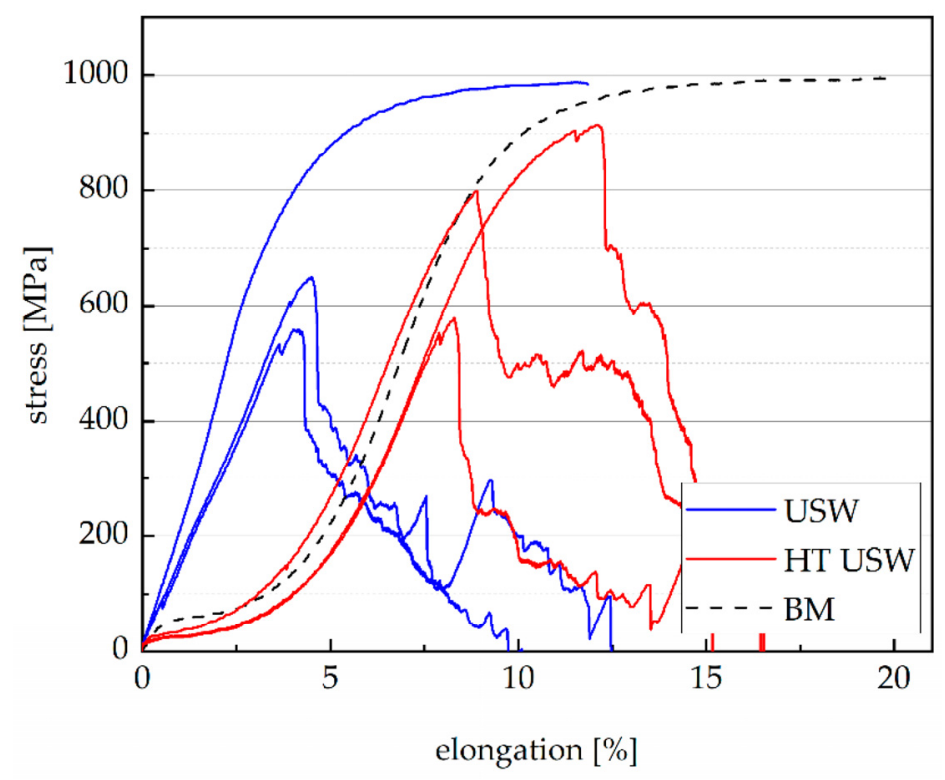

Figure 3. Stress/elongation behavior of heat-treated and non-heat-treated USW joints and BM.

Due to the atypical SMA behavior of the welded joints, it seems that the high-frequency oscillations and the welding pressure of the USW process influenced the microstructure of the wire. To reduce the number of possible dislocations, and in order to detwin the martensite, a recovery could be helpful. Therefore, the joints were put into an oven and heated up for $10 \mathrm{~min}$ at $170{ }^{\circ} \mathrm{C}$. This heat treatment led to a typical behavior of SMAs regarding tensile testing results. The martensite plateau follows the first linear-elastic rise but at a lower stress than the BM. After that, the ultimate joint strength of all joints increases at different levels $(579,799,914 \mathrm{MPa})$. In comparison to the welded joints without heat treatment, every joint has a longer elongation $(15.1 \%, 16.4 \%, 16.5 \%)$. However, despite the heat treatment, all three joints were not broken. Instead, the wires were pulled out of the ferrules.

\subsection{Electrical Resistance}

Compared to the stress/elongation curves, the stress/electrical resistance behavior (Figure 4) is similar. The detwinning of the martensitic BM resulted in an increase of the electrical resistance from 5 to $5.5 \Omega$, while the stress remained almost on the same level. In the state of the second linear-elastic expansion, the electrical resistance increased with increasing stress. As soon as the plastic deformation began as a result of dislocation movement, the electrical resistance increased to $7.45 \Omega$, while the stress increased more slowly.

The heat-treated joints show the same behavior as the BM but with a delay of approx. $1 \Omega$ and a maximum electrical resistance of $7.7 \Omega$. In addition, all three curves are replicable until the wires were pulled out of the ferrule and the stress dropped.

This behavior of wires slipping out of the ferrule is also seen at the non-heat-treated USW joints. However, the untreated joints show no increase in electrical resistance, as would be the case during the martensite plateau. The behavior of stress/electrical resistance of the heat-treated and non-heat-treated joints is, therefore, similar to the stress/elongation behavior. 


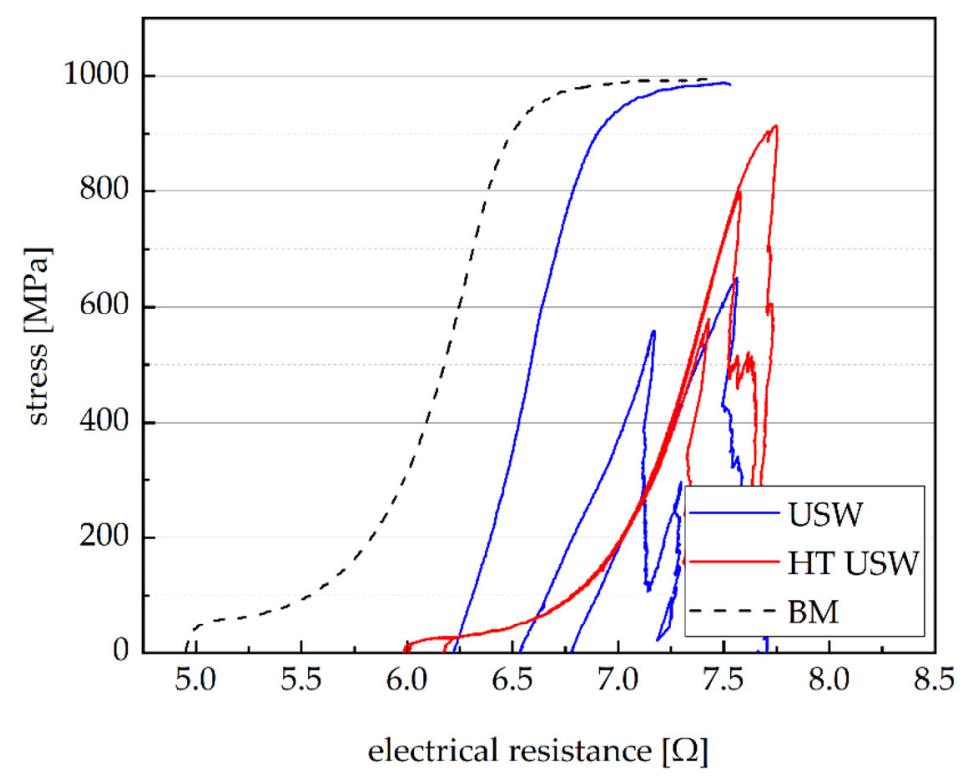

Figure 4. Stress-electrical resistance behavior of heat-treated and non-heat-treated USW joints and BM.

\subsection{Scanning Electron Microscopy}

An overview picture of the BM wire was made at a magnification of $250 \times$ (Figure 5a). In this picture, the round wire with a knurl on the rim is clear to see. This knurl is a result of the wire-forming process and is shown in Figure $5 b$ at a higher magnification of $5000 \times$. At the edge of the wire, there is a brighter phase than the BM is. As a consequence of the fact that the heavy elements on SEM images are more luminous, the bright phase could have a high proportion of the heaviest element of the $\mathrm{BM}$, which means that the outer layer is rich in nickel. This thesis got verified by EDS in the following chapter.

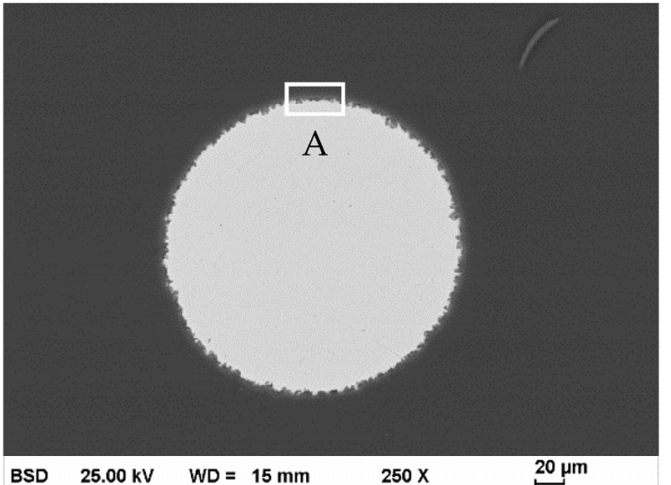

(a)

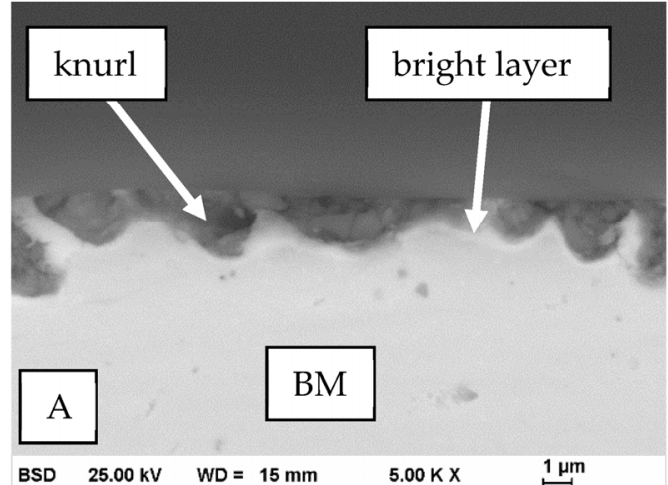

(b)

Figure 5. SEM pictures of the wire BM with a magnification of (a) $250 \times$ and (b) $5000 \times$.

After welding, an SEM picture of the whole joint was taken (Figure 6). It demonstrates that only the ferrule is plastically deformed due to the welding pressure of the horn, while the wire is nearly in the same shape as the $\mathrm{BM}$ is. This is the consequence of the higher hardness of the NiTiCu (298 HV [24]) compared to the silver-coated copper (bare copper: $54 \mathrm{HV}$ [25]). Because of the larger diameter of the ferrule and the uniaxial movement of the horn, cavities are formed on the right and left sides between the wire and the ferrule. However, a form-fitting connection between both joining partners can be seen on the horn and anvil sides of the joint but with a crack on the upper welding zone. 


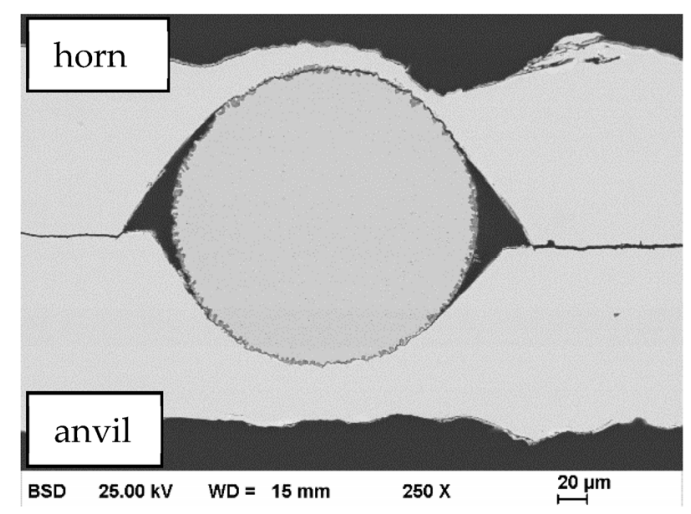

Figure 6. SEM picture of the USWed joint with a magnification of $250 \times$.

This crack can be seen in greater detail at $2500 \times$ magnification (Figure 7a). In addition, there are various zones around the crack. The bright layer which was detected on the edge of the BM is also in the welded joint to see. Furthermore, another compound is developed in the welding zone between the ferrule and the wire with a different structure in comparison to the bright layer and the BM. Additionally, this phase is scattered with lots of micro cracks. In order to check the composition of this phase, EDS was carried out in the following chapter.

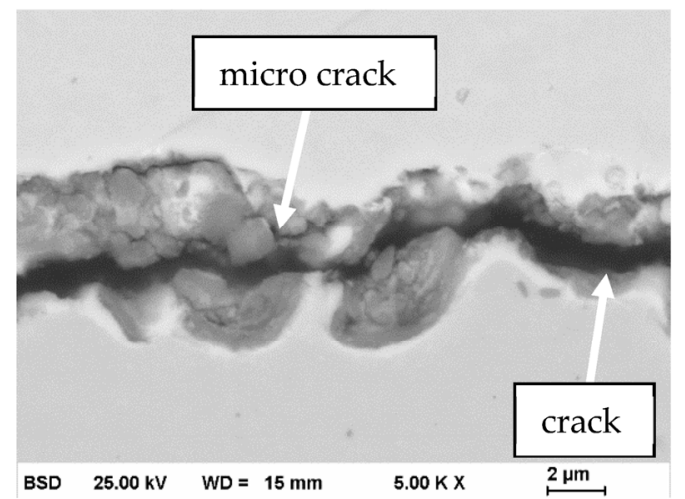

(a)



(b)

Figure 7. SEM pictures of the welding zone of (a) the horn side and (b) the anvil side by a $5000 \times$.

The developed phase and the bright layer are located on the anvil side and on the horn side of the welded joint, but the phase on the anvil side has a lower number of micro cracks. Moreover, the crack between the form-filled joining partners is smaller than on the horn side.

\subsection{Energy-Dispersive X-ray Spectroscopy}

EDS was carried out to analyze the composition of different phases. Therefore, the $\mathrm{BM}$, the bright layer, the welding zone of the horn side and the welding zone of the anvil side were each measured once.

The result of the EDS of the BM revealed that it is composed of 49 at.\% titanium, 43 at. $\%$ nickel and 8 at.\% copper. Because of the proportion of 8 at.\% copper, the substitution of nickel did not influence the transformation from the cubic B2 austenite to the monoclinic B19' martensite. Therefore, this BM of the NiTiCu SMA has the same structure as in the binary TiNi-system [26].

To investigate the bright layer (Figure 7b), a position in the welding zone of the anvil side where the layer is more pronounced was examined because of the small size of less than $1 \mu \mathrm{m}$, which is too small for a reliable analysis (the Kanaya-Okayama Range of titanium at $25 \mathrm{keV}$ is $4.06 \mu \mathrm{m}$ [27]). However, a higher proportion of nickel (52 at.\%) was 
measured. This result confirms the thesis of the SEM investigation; the bright layer is rich in nickel. Furthermore, the silver of the coating of the ferrules is found in this layer at a proportion of 2 at. $\%$, and the copper rises up to a maximum of 18 at. $\%$.

The welding of the BM to the copper ferrule is included with an increase of the content of copper up to 13 at.\% on the horn side. In addition, the nickel-rich layer affects the welding zone too. Therefore, the proportion of nickel rises up to 48 at. $\%$, while the titanium decreases to 39 at.\%. This change of composition shows that a different phase was generated during the USW process.

In comparison, the phase of the welding zone of the anvil side has a similar copper proportion (13 at.\%) to that of the opposite side, while the amount of titanium is 51 at.\%. This decreases the nickel content to 36 at. $\%$.

\subsection{Differential Scanning Calorimetry}

The transition temperatures were determined by heating and cooling the $\mathrm{BM}$ and the welded joint between 0 and $100{ }^{\circ} \mathrm{C}$. First, the specimen was heated up to $100{ }^{\circ} \mathrm{C}$ to recover the materials from lattice defects and dislocations, which are typical results of the USW process but especially of the normal handling while cutting the materials to the correct specimen geometry. For this reason, the first heating curve is not comparable, and therefore, is not shown in Figure 8.

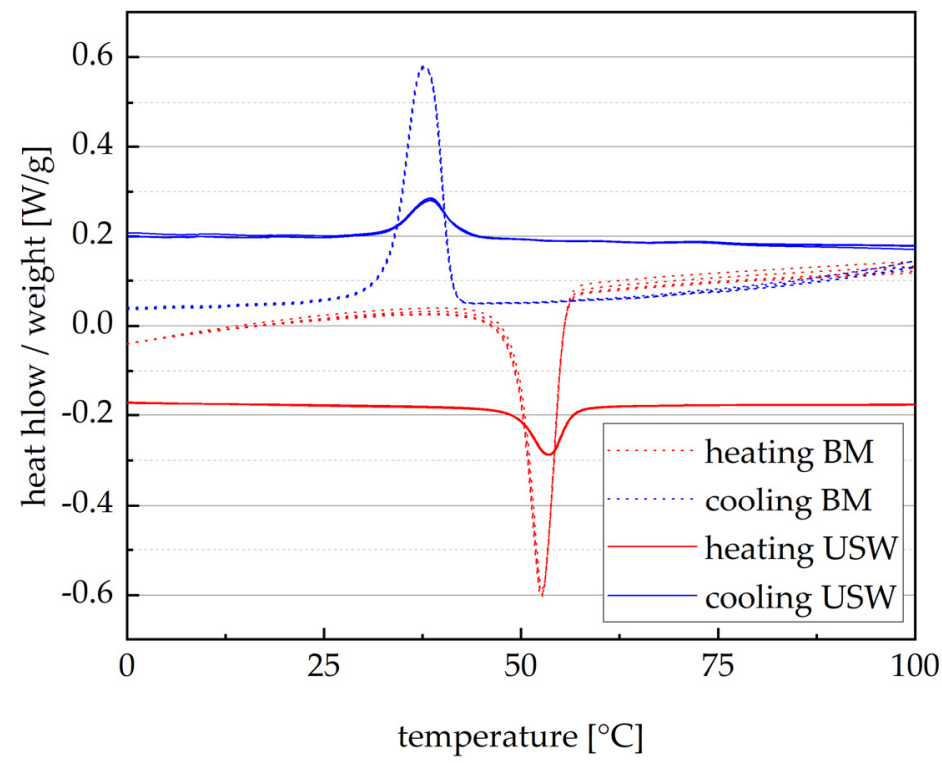

Figure 8. DSC measurements for the NiTiCu BM wire and the US welded joint of the NiTiCu wire and the silver-coated ferrule.

The measurement of the DSC reveals the transition temperatures of the $\mathrm{BM}$ $\left(A_{s}=49.42{ }^{\circ} \mathrm{C}, A_{f}=55.61{ }^{\circ} \mathrm{C}, M_{s}=41.26{ }^{\circ} \mathrm{C}, M_{f}=33.4{ }^{\circ} \mathrm{C}\right)$ by an endothermic heat $\Delta Q_{p}$ of $-17.24 \mathrm{~J} / \mathrm{g}$ and an exothermic heat $\Delta Q_{m}$ of $17.97 \mathrm{~J} / \mathrm{g}$. Furthermore, the curves of the transition temperatures of the BM are nearly the same. This indicates that the wire is not stabilized, which means that it is rich in lattice defects and dislocations. This could be a consequence of cutting the wires or the wire forming process.

Because of the limited space for the sample in the DSC analysis system, only one welded joint could be analyzed. This joint has a weight of $20.42 \mathrm{mg}$, which includes the SMA wire $(1.65 \mathrm{mg})$ and the non-SMA ferrule $(18.77 \mathrm{mg})$. In comparison to the $\mathrm{BM}$, the quantity of SMA material is 2.982 times less. Due to this and the ferrule covering the SMA wire, the DSC signal of the transition temperatures of the SMA is much smaller than that of the BM but can still be measured reliably. In Figure 8, the heat flow per weight of the welded joint is multiplied by the factor of 2.982 to compare the different curves by the same weight of the SMA material. The DSC curves of the joint due to heating and cooling 
are similar and also not stabilized. Their endothermic and exothermic heat is 3.46 and $3.59 \mathrm{~J} / \mathrm{g}$, respectively. Furthermore, the transition temperatures of the US welded joint were determined as $A_{s}=49.26, A_{f}=56.7, M_{s}=42.42$ and $M_{f}=33.18{ }^{\circ} \mathrm{C}$.

\section{Discussion}

Only one specimen of the welded joints was broken in tensile testing, while all the other wires were pulled out of the ferrules. This broken specimen has an ultimate tensile strength of almost $100 \%$ compared to the BM, which means that the joint strength could be higher than the ultimate tensile strength of the wire. The reason why only one joint has this high degree of strength could be that the wires are often not connected to the ferrule to the maximum extend, which is also seen in the SEM pictures because of cracks and microcracks in the welding zones. This can be a consequence of the fact that the welding energy is too high, causing the destruction of micro-connections in the welding zone after joining, which is especially the case on the horn side since the energy on the anvil side is dampened by softening effects. However, the non-broken joints achieved tensile strengths between $56 \%$ and $92 \%$, which underlines the high potential of the solid-state welding process. Furthermore, the joints do not have a martensitic plateau after welding, which implies the martensite is completely detwinned. However, after a heat treatment over $A_{f}$, the SMA behavior is completely rebuilt without any delay of elongation or stress. This means that the USW process deforms the SMA wires only by detwinning martensite and without creating dislocations.

The rebuilt SMA behavior after heat treatment is also observed in the change of the electrical resistance during tensile tests. The delay of $1 \Omega$ versus the BM could be due to the cracks and microcracks in the welding zone, which increase the total electrical resistance. Additionally, the newly generated compound of the welding zone could also influence the electrical resistance. Moreover, the similar behavior of stress/elongation and stress/electrical resistance is the consequence of the changed microstructure under load. Based on an expansion of stress, the martensite detwins, and the number of dislocations grows. In relation to Matthiessen's rule, which means that the resistivity of the metal rises with the increasing number of lattice defects, the stress/elongation and stress/electrical resistance must behave similarly.

The EDS revealed that the proportion of copper in the welding zone of the anvil side is 13 at. $\%$ and, therefore, is higher than the NiTiCu BM (8 at.\%). For a quantity of almost 50 at.\% titanium, this indicates that the transition of the BM from the cubic B2 austenite to the monoclinic B19' martensite must change. Therefore, if the temperature falls below $M_{f}$, the B2 austenite will transform into orthorhombic B19 martensite as long as the ambient temperature is more than $250 \mathrm{~K}$ [26]. In comparison, the welding zone of the horn side has a similar copper content, but that of titanium is only 39 at.\%. This could mean that the welding zone of the horn side has a different phase composition than that of the anvil side. However, the welding temperatures of both sides should be similar, and the compositions of the joining partners are the same. In addition, the atomic radii of nickel and copper are comparable [28], making the substitution of nickel by copper more plausible than of titanium. These reasons show that the welding zone of the anvil side must be similar to the horn side. The difference in the composition is due to the fact that the welding zone at the horn is not a homogeneous phase. Rather, the zone is divided into lots of micro-pieces of the NiTiCu wire and the copper ferrule, which is also seen in the SEM picture (Figure 7a).

A lower endothermic and exothermic heat was found with DSC compared to the BM. This is a consequence of the decrease in the quantity of the SMA BM and of the isolation of the wire through the ferrule so that only a small signal is detectable. However, the transition temperatures could be determined reliably. Contrary to fusion welding processes, the DSC revealed that the USW exhibited only minor influences on the transition temperatures of the SMAs. It should also be helpful that the second joining partner is copper, for the reason that the higher composition of copper in the welding zone does not affect the transition temperatures, while orthorhombic B19 martensite is formed instead of monoclinic B19' 
martensite [26]. In addition, the SEM images did show that the welding zones are not wider than $10 \mu \mathrm{m}$, which means that the welding zones only have a minimal effect on the transition temperatures.

\section{Conclusions}

In this study, mechanical and microstructural characterizations of USWed $\mathrm{NiTiCu}$ wires to silver-coated ferrules were carried out. The results of the various analyses revealed:

- $\quad$ All NiTiCu wires could be USWed to silver-coated ferrules.

- One wire of the welded joints was not pulled out of the ferrule and exhibited an ultimate tensile strength of almost $100 \%$ compared to the BM, which shows the high potential of the USW process.

- Due to USW, the martensite of the SMA wires was detwinned. After a heat treatment above $A_{f}$, the typical SMA behavior was rebuilt.

- The stress/electrical resistance behavior is comparable to that of stress/elongation.

- EDS did show a higher composition of copper in the welding zone, which led to the transition of $\mathrm{B} 2 \rightarrow \mathrm{B} 19$ instead of $\mathrm{B} 2 \rightarrow \mathrm{B} 19^{\prime}$.

- The new structure of the generated welding zone and the USW process did not affect the transition temperatures of the SMA.

Author Contributions: Conceptualization, T.S., A.G., G.W., T.M. and W.-G.D.; methodology, T.S., A.G. and T.M.; formal analysis, T.S., A.G. and G.W.; investigation, T.S., A.G., G.W., T.M., B.S. and W.-G.D.; resources, G.W. and W.-G.D.; writing-original draft preparation, T.S.; writing—review and editing, T.S., A.G., G.W., T.M., B.S. and W.-G.D.; visualization, T.S. and A.G.; supervision, T.S., A.G., G.W., T.M. and W.-G.D.; project administration, A.G., G.W., T.M. and W.-G.D.; funding acquisition, A.G., G.W., T.M. and W.-G.D. All authors have read and agreed to the published version of the manuscript.

Funding: The publication of this article was funded by the Chemnitz University of Technology.

Data Availability Statement: Not applicable.

Acknowledgments: We thankfully acknowledge Mario Scholze for carrying out the DSC measurements and Husam Ahmad for investigating the joints by SEM and EDS.

Conflicts of Interest: The authors declare no conflict of interest.

\section{References}

1. Ikuta, K. Micro/miniature shape memory alloy actuator. In Proceedings of the IEEE International Conference on Robotics and Automation, Cincinnati, OH, USA, 13-18 May 1990; pp. 2156-2161, ISBN 0-8186-9061-5.

2. Gorbet, R.B.; Russell, R.A. A novel differential shape memory alloy actuator for position control. Robotica 1995, 13, 423-430. [CrossRef]

3. Huang, X.; Kumar, K.; Jawed, M.K.; Mohammadi Nasab, A.; Ye, Z.; Shan, W.; Majidi, C. Highly Dynamic Shape Memory Alloy Actuator for Fast Moving Soft Robots. Adv. Mater. Technol. 2019, 4, 1800540. [CrossRef]

4. Hannula, S.P.; Söderberg, O.; Jämsä, T.; Lindroos, V.K. Shape Memory Alloys for Biomedical Applications. Mater. Clin. Appl. VII 2006, 49, 109-118. [CrossRef]

5. Yoneyama, T.; Miyazaki, S. Shape Memory Alloys for Biomedical Applications; Elsevier: Amsterdam, The Netherlands, 2008; ISBN 9781845695248.

6. Costanza, G.; Tata, M.E. Shape Memory Alloys for Aerospace, Recent Developments, and New Applications: A Short Review. Matererials 2020, 13, 1856. [CrossRef]

7. Jani, J.M.; Leary, M.; Subic, A. Shape Memory Alloys in Automotive Applications. Automot. Eng. Mobil. Res. 2014, 663, $248-253$. [CrossRef]

8. Ma, J.; Karaman, I.; Noebe, R.D. High temperature shape memory alloys. Int. Mater. Rev. 2010, 55, 257-315. [CrossRef]

9. Lagoudas, D.C. Shape Memory Alloys: Modeling and Engineering Applications; Springer: Boston, MA, USA, 2008; ISBN 978-0-38747684-1.

10. Funakubo, H. (Ed.) Shape Memory Alloys; CRC Press: Boca Raton, FL, USA, 1984; ISBN 2881241360.

11. Oliveira, J.P.; Barbosa, D.; Fernandes, F.M.B.; Miranda, R.M. Tungsten inert gas (TIG) welding of Ni-rich NiTi plates: Functional behavior. Smart Mater. Struct. 2016, 25, 03LT01. [CrossRef]

12. Ikai, A.; Kimura, K.; Tobushi, H. TIG Welding and Shape Memory Effect of TiNi Shape Memory Alloy. J. Intell. Mater. Syst. Struct. 1996, 7, 646-655. [CrossRef] 
13. Yang, D.; Jiang, H.C.; Zhao, M.J.; Rong, L.J. Microstructure and mechanical behaviors of electron beam welded NiTi shape memory alloys. Mater. Des. 2014, 57, 21-25. [CrossRef]

14. Krooß, P.; Günther, J.; Halbauer, L.; Vollmer, M.; Buchwalder, A.; Zenker, R.; Biermann, H.; Niendorf, T. Electron beam welding of Fe-Mn-Al-Ni shape memory alloy: Microstructure evolution and shape memory response. Funct. Mater. Lett. 2017, 10, 1750043. [CrossRef]

15. Oliveira, J.P.; Miranda, R.M.; Braz Fernandes, F.M. Welding and Joining of NiTi Shape Memory Alloys: A Review. Prog. Mater. Sci. 2017, 88, 412-466. [CrossRef]

16. Falvo, A.; Furgiuele, F.M.; Maletta, C. Laser welding of a NiTi alloy: Mechanical and shape memory behaviour. Mater. Sci. Eng. A 2005, 412, 235-240. [CrossRef]

17. Zeng, Z.; Yang, M.; Oliveira, J.P.; Song, D.; Peng, B. Laser welding of NiTi shape memory alloy wires and tubes for multi-functional design applications. Smart Mater. Struct. 2016, 25, 85001. [CrossRef]

18. Prabu, S.M.; Madhu, H.C.; Perugu, C.S.; Akash, K.; Mithun, R.; Kumar, P.A.; Kailas, S.V.; Anbarasu, M.; Palani, I.A. Shape memory effect, temperature distribution and mechanical properties of friction stir welded nitinol. J. Alloys Compd. 2019, 776, 334-345. [CrossRef]

19. Lima, J.S.; Neto, A.C.W.; De Melo, R.H.F. Friction Stir Welding of Austenitic NiTi Shape Memory Alloys. Glob. J. Res. Eng. 2017, 17. Available online: https:/ / engineeringresearch.org/index.php/GJRE/article/view/1596 (accessed on 1 October 2021).

20. Man, H.C.; Zhao, N.Q. Enhancing the adhesive bonding strength of NiTi shape memory alloys by laser gas nitriding and selective etching. Appl. Surf. Sci. 2006, 253, 1595-1600. [CrossRef]

21. Niccoli, F.; Alfano, M.; Bruno, L.; Furgiuele, F.; Maletta, C. Mechanical and Functional Properties of Nickel Titanium Adhesively Bonded Joints. J. Mater. Eng. Perform. 2014, 23, 2385-2390. [CrossRef]

22. Zhang, W.; Ao, S.S.; Oliveira, J.P.; Zeng, Z.; Luo, Z.; Hao, Z.Z. Effect of ultrasonic spot welding on the mechanical behaviour of NiTi shape memory alloys. Smart Mater. Struct. 2018, 27, 85020. [CrossRef]

23. Zhang, W.; Ao, S.; Oliveira, J.P.; Zeng, Z.; Huang, Y.; Luo, Z. Microstructural Characterization and Mechanical Behavior of NiTi Shape Memory Alloys Ultrasonic Joints Using Cu Interlayer. Materials 2018, 11, 1830. [CrossRef] [PubMed]

24. Santosh, S.; Sampath, V. Experimental investigations on the effect of copper on the microstructure and shape memory characteristics of NiTi alloys. IOP Conf. Ser. Mater. Sci. Eng. 2020, 912, 52009. [CrossRef]

25. Uno, T. Enhancing bondability with coated copper bonding wire. Microelectron. Reliab. 2011, 51, 88-96. [CrossRef]

26. Tang, W.; Sandström, R.; Wei, Z.G.; Miyazaki, S. Experimental investigation and thermodynamic calculation of the Ti-Ni-Cu shape memory alloys. Met. Mater. Trans. A 2000, 31, 2423-2430. [CrossRef]

27. Kanaya, K.; Okayama, S. Penetration and energy-loss theory of electrons in solid targets. J. Phys. D Appl. Phys. 1972, 5, 43-58. [CrossRef]

28. Winter, M. The Periodic Table of the Elements by WebElements. Available online: https://www.webelements.com/ (accessed on 14 September 2021). 